\title{
DIDÁTICA EM DOCÊNCIA DO ENSINO SUPERIOR: (IN)SUCESSO DO ENSINO-APRENDIZAGEM NA INTERAÇÃO PROFESSOR-ALUNO
}

\section{ARTIGO DE REVISÃO}

OLIVEIRA, Wellington da Silva ${ }^{1}$

OLIVEIRA, Wellington da Silva. Didática em docência do ensino superior: (in)sucesso do ensino-aprendizagem na interação professor-aluno. Revista Científica Multidisciplinar Núcleo do Conhecimento. Ano 05, Ed. 04, Vol. 03, pp. 2740. Abril de 2020. ISSN: 2448-0959, Link de acesso: https://www.nucleodoconhecimento.com.br/educacao/didatica-em-docencia

\section{RESUMO}

A didática em docência do ensino superior envolve dois atores, o professor e o aluno, em torno do conhecimento. $O$ docente necessita de dois conhecimentos para sua prática educacional, a saber, o conteúdo e a didática. O estudo objetivou levantar produções científicas sobre a didática em docência do ensino superior, o insucesso e sucesso do processo de ensino-aprendizagem na interação professor-aluno. Trata-se de uma pesquisa descritiva quanti-qualitativa de revisão sistemática em banco de dados online por meio dos descritores "didática e ensino superior"; "pedagogia e ensino superior"; e "ensino-aprendizagem e ensino superior". $O$ artigo está embasado na concepção pedagógica de Paulo Freire, Libâneo, Perrenoud, Rubem Alves e Margaret Mead, entre outros. Nos resultados observam-se as diferentes alternativas para prática didática; a persistência na educação tradicional em detrimento da educação moderna; burocracias institucionais para novas propostas; baixa valorização do profissional; a inclusão das tecnologias da informação e comunicação na educação; a importância da afetividade para o processo ensino-aprendizado; o

\footnotetext{
${ }^{1}$ Pós-Graduação em Docência do Ensino Superior e em Gênero e Sexualidade pela Faculdade Dom Alberto, Pós-Graduação em Saúde Pública pelo Centro Universitário São Camilo e Graduação em Psicologia pela Universidade Nove de Julho.
} 
professor como motivador do aluno; o aluno como ser ativo em seu processo de construção do conhecimento para leitura de sua realidade. Conclui-se que todos estes apontamentos servirão para o insucesso ou sucesso educacional.

Palavras-Chave: docência, didática, pedagogia, ensino-aprendizagem, Ensino Superior.

\section{INTRODUÇÃO}

A profissão docente brasileira, no ensino superior, supõe quarto níveis de formação para o acesso e o avanço na vivência acadêmica, a saber: auxiliar, assistente, adjunto e titular. O primeiro necessita de graduação (ou especialização), o segundo mestrado, o terceiro doutorado e o quarto, além do doutorado, uma grande produção de trabalhos (CUNHA; BRITO; CICILLINI, 2004).

A Didática em Docência do Ensino Superior (DES) implica no complexo processo de ensino e aprendizagem que envolve dois atores: o docente e o discente, ou seja, o professor e o aluno. A prática educacional envolve sujeitos cognoscentes, professor e aluno, em torno do objeto cognoscível, conhecimento, visando à formação humana em contexto situado (CRUZ, 2017). Em geral, destacam-se dois tipos de conhecimentos que os docentes precisam para ensinar: o dos conteúdos e o pedagógico (ENRICONE, 2008).

O conceito de docência e didática, embora relacionados, tem sido utilizados de maneira equivocada como sinônimos. Há uma diferença a ser esclarecida, a primeira refere-se ao ato de ensinar, ministrar aulas ou exercer o magistério; a segunda referese ao modo de transmitir conhecimentos ou ensinar. Docência é o processo desenvolvido por quem assume a função de professor. Didática é o domínio do conhecimento sobre o processo ensino-aprendizagem. Ensinar e fazer o aluno aprender é a didática em si. A didática inclui as teorizações e fundamentações conceituais e procedimentais sobre a relação entre professor e alunos em torno do conhecimento em situações determinadas de ensinar e aprender (CRUZ, 2017). 
Tal pesquisa se justifica pelo fato da prática educacional e a qualidade do ensino estarem estritamente relacionadas à formação pedagógica do profissional que se propõe a lecionar. A docência exige muito mais que o domínio do conteúdo específico da área, requer recursos didáticos, ou seja, o seu modo de proceder. Além da formação específica numa área de conhecimento e experiência profissional, é preciso o domínio de habilidades didático-pedagógicas. Por tanto, para o profissional bacharelado atuar ministrando aulas precisa minimamente de uma especialização em docência do ensino superior.

A falta de preparação dos profissionais para lecionar gera dificuldades de aprendizagem nos educandos. Então, não raramente, nos deparamos com os discursos de professores como "eu ensinei o conteúdo, o aluno que não aprendeu". Às vezes, até rotulando o educando com algum distúrbio ou patologia, para alegar seu não aprendizado e desenvolvimento. Cabe nos questionar se a dificuldade comumente apontada como problemas de "aprendizagem" possa ser de "ensinagem" (POLITY, 2002).

Por isto, é importante que o professor amplie esta visão que coloca o aluno como único responsável por sua dificuldade e busque recursos alternativos para que ele aprenda. Neste sentido, este trabalho se propõe a trazer uma reflexão sobre a prática docente e seus meios optativos. O objetivo desta pesquisa é realizar um levantamento bibliográfico de produções científicas recentes, análise dos resultados e discussão, sobre a didática em docência do ensino superior, o insucesso e sucesso do processo de ensino-aprendizagem na interação professor-aluno universitário.

A presente pesquisa descritiva quanti-qualitativa foi realizada por meio de uma revisão sistemática consultando-se os bancos de dados digitais Scientific Eletronic Library Online (SciELO) e Google Acadêmico (GA), dos últimos 10 anos (2008-2018), e livros com propostas didáticas. A pesquisa foi realizada com os seguintes descritores: Didática e Ensino Superior; Pedagogia e Ensino Superior; e Ensino-Aprendizagem e Ensino Superior. O artigo está embasado na concepção pedagógica de diversos autores, dentre estes FREIRE, Paulo (1996); LIBÂNEO, José Carlos (1990); 
PERRENOUD, Philippe (2000a, 2000b); ALVES, Rubem (2000, 2001, 2010); MEAD, Margaret (1961).

\section{RESULTADO E DISCUSSÃO}

Através da pesquisa bibliográfica foram encontrados artigos sobre o tema didática, pedagogia e ensino-aprendizagem no ensino superior. Após, estruturou-se no quadro abaixo com as seguintes colunas: ano da publicação, autor(es), título, revista e descritor. Em seguida, apresentam-se resumos dos artigos encontrados e discussão com os livros referência para a prática didática.

Quadro 1 - Pesquisas bibliográficas realizadas nos bancos de dados online SciELOe Google Acadêmico com os descritores Didática e Ensino Superior, Pedagogia e Ensino Superior, e Ensino-Aprendizagem e Ensino Superior.

\begin{tabular}{|c|c|c|c|c|}
\hline $\begin{array}{l}\text { Ano da } \\
\text { Publicação }\end{array}$ & Autor(es) & Título & Revista & Descritor \\
\hline 2008 & Esteves, M. & $\begin{array}{l}\text { Para a excelência } \\
\text { pedagógica do ensino } \\
\text { superior }\end{array}$ & $\begin{array}{l}\text { Sísifo. } \\
\text { Revista de } \\
\text { Ciências da } \\
\text { Educação }\end{array}$ & $\begin{array}{l}\text { Ensino- } \\
\text { Aprendizagem } \\
\text { e Ensino } \\
\text { Superior }\end{array}$ \\
\hline 2009 & $\begin{array}{l}\text { Cavaliere } \\
\text { Junior, E; et } \\
\text { al. }\end{array}$ & $\begin{array}{l}\text { A afetividade e a } \\
\text { aprendizagem na } \\
\text { docência do ensino } \\
\text { superior }\end{array}$ & $\begin{array}{l}\text { Revista } \\
\text { Digital }\end{array}$ & $\begin{array}{l}\text { Ensino- } \\
\text { Aprendizagem } \\
\text { e Ensino } \\
\text { Superior }\end{array}$ \\
\hline 2010 & $\begin{array}{l}\text { Albuquerque, } \\
\text { C. }\end{array}$ & $\begin{array}{l}\text { Processo ensino- } \\
\text { aprendizagem: } \\
\text { características do } \\
\text { professor eficaz }\end{array}$ & Millenium & $\begin{array}{l}\text { Ensino- } \\
\text { Aprendizagem } \\
\text { e Ensino } \\
\text { Superior }\end{array}$ \\
\hline 2011 & $\begin{array}{l}\text { Rodrigues, } \\
\text { LP; Moura, } \\
\text { LS; Testa, E. }\end{array}$ & $\begin{array}{l}O \text { tradicional e } \\
\text { moderno quanto à }\end{array}$ & $\begin{array}{l}\text { Revista } \\
\text { Científica do } \\
\text { ITPAC }\end{array}$ & $\begin{array}{l}\text { Didática e } \\
\text { Ensino } \\
\text { Superior }\end{array}$ \\
\hline
\end{tabular}




\begin{tabular}{|c|c|c|c|c|}
\hline & & $\begin{array}{l}\text { didática do ensino } \\
\text { superior }\end{array}$ & & \\
\hline 2013 & $\begin{array}{l}\text { Santo, EE; } \\
\text { Luz, LCS. }\end{array}$ & $\begin{array}{l}\text { Didática no ensino } \\
\text { superior: perspectivas } \\
\text { e desafios }\end{array}$ & Saberes & $\begin{array}{l}\text { Didática } \\
\text { Ensino } \\
\text { Superior }\end{array}$ \\
\hline 2014 & Valente, JA. & $\begin{array}{l}\text { Blended learning e as } \\
\text { mudanças no ensino } \\
\text { superior: a proposta } \\
\text { da sala de aula } \\
\text { invertida }\end{array}$ & $\begin{array}{l}\text { Educar em } \\
\text { Revista }\end{array}$ & $\begin{array}{l}\text { Ensino- } \\
\text { Aprendizagem } \\
\text { e Ensino } \\
\text { Superior }\end{array}$ \\
\hline 2014 & $\begin{array}{l}\text { Oliskovicz, K; } \\
\text { Piva, CD. }\end{array}$ & $\begin{array}{l}\text { As estratégias } \\
\text { didáticas no ensino } \\
\text { superior: quando é o } \\
\text { momento certo para } \\
\text { se usar as estratégias } \\
\text { didáticas no ensino } \\
\text { superior? }\end{array}$ & $\begin{array}{l}\text { Revista de } \\
\text { Educação }\end{array}$ & $\begin{array}{l}\text { Didática } \\
\text { Ensino } \\
\text { Superior }\end{array}$ \\
\hline 2015 & $\begin{array}{l}\text { Freire, LIF; } \\
\text { Fernandez, } \\
\text { C. }\end{array}$ & $\begin{array}{l}\text { O professor } \\
\text { universitário novato: } \\
\text { tensões, dilemas e } \\
\text { aprendizados no início } \\
\text { da carreira docente }\end{array}$ & $\begin{array}{ll}\text { Ciência } & \text { e } \\
\text { Educação } & \end{array}$ & $\begin{array}{l}\text { Didática } \\
\text { Ensino } \\
\text { Superior }\end{array}$ \\
\hline 2016 & David, RS. & $\begin{array}{l}\text { Docência na } \\
\text { contemporaneidade: } \\
\text { desafios para } \\
\text { docentes no ensino } \\
\text { superior }\end{array}$ & $\begin{array}{l}\text { Caderno de } \\
\text { Letras }\end{array}$ & $\begin{array}{l}\text { Pedagogia } \\
\text { Ensino } \\
\text { Superior }\end{array}$ \\
\hline 2017 & Cruz, GB. & $\begin{array}{l}\text { Didática e docência } \\
\text { no ensino superior }\end{array}$ & $\begin{array}{l}\text { Revista } \\
\text { Brasileira de } \\
\text { Estudos } \\
\text { Pedagógicos }\end{array}$ & $\begin{array}{l}\text { Didática } \\
\text { Ensino } \\
\text { Superior }\end{array}$ \\
\hline
\end{tabular}


Fonte: Autor.

Chart 1 - Bibliographic searches carried out in the online databases SciELO and Google Scholar with the descriptors Didactics and Higher Education, Pedagogy and Higher Education, and Teaching-Learning and Higher Education.

\begin{tabular}{|c|c|c|c|c|}
\hline $\begin{array}{l}\text { Year of } \\
\text { Publication }\end{array}$ & Author (s) & Title & Magazine & Descriptor \\
\hline 2008 & Esteves, M. & $\begin{array}{l}\text { Towards pedagogical } \\
\text { excellence in higher } \\
\text { education }\end{array}$ & $\begin{array}{l}\text { Sísifo. Revista } \\
\text { de Ciências da } \\
\text { Educação }\end{array}$ & $\begin{array}{l}\text { Teaching- } \\
\text { Learning } \\
\text { and Higher } \\
\text { Education }\end{array}$ \\
\hline 2009 & $\begin{array}{l}\text { Cavaliere } \\
\text { Junior, E; et } \\
\text { al. }\end{array}$ & $\begin{array}{l}\text { Affection and learning in } \\
\text { higher education } \\
\text { teaching }\end{array}$ & Revista Digital & $\begin{array}{l}\text { Teaching- } \\
\text { Learning } \\
\text { and Higher } \\
\text { Education }\end{array}$ \\
\hline 2010 & $\begin{array}{l}\text { Albuquerque, } \\
\text { C. }\end{array}$ & $\begin{array}{l}\text { Teaching-learning } \\
\text { process: characteristics } \\
\text { of the effective teacher }\end{array}$ & Millenium & $\begin{array}{l}\text { Teaching- } \\
\text { Learning } \\
\text { and Higher } \\
\text { Education }\end{array}$ \\
\hline 2011 & $\begin{array}{l}\text { Rodrigues, } \\
\text { LP; Moura, } \\
\text { LS; Testa, E. }\end{array}$ & $\begin{array}{l}\text { The traditional and the } \\
\text { modern regarding the } \\
\text { teaching of higher } \\
\text { education }\end{array}$ & $\begin{array}{l}\text { Revista } \\
\text { Científica do } \\
\text { ITPAC }\end{array}$ & $\begin{array}{l}\text { Didactics } \\
\text { and Higher } \\
\text { Education }\end{array}$ \\
\hline 2013 & $\begin{array}{l}\text { Santo, } \quad \text { EE; } \\
\text { Luz, LCS. }\end{array}$ & $\begin{array}{l}\text { Didactics in higher } \\
\text { education: perspectives } \\
\text { and challenges }\end{array}$ & Saberes & $\begin{array}{l}\text { Didactics } \\
\text { and Higher } \\
\text { Education }\end{array}$ \\
\hline 2014 & Valente, JA. & $\begin{array}{l}\text { Blended learning and } \\
\text { changes in higher } \\
\text { education: the inverted } \\
\text { classroom proposal }\end{array}$ & $\begin{array}{l}\text { Educar } \\
\text { Revista }\end{array}$ & $\begin{array}{l}\text { Teaching- } \\
\text { Learning } \\
\text { and Higher } \\
\text { Education }\end{array}$ \\
\hline
\end{tabular}




\begin{tabular}{|c|c|c|c|c|}
\hline 2014 & $\begin{array}{l}\text { Oliskovicz, K; } \\
\text { Piva, CD. }\end{array}$ & $\begin{array}{l}\text { Didactic strategies in } \\
\text { higher education: when } \\
\text { is the right time to use } \\
\text { didactic strategies in } \\
\text { higher education? }\end{array}$ & $\begin{array}{l}\text { Revista de } \\
\text { Educação }\end{array}$ & $\begin{array}{l}\text { Didactics } \\
\text { and Higher } \\
\text { Education }\end{array}$ \\
\hline 2015 & $\begin{array}{l}\text { Freire, LIF; } \\
\text { Fernandez, } \\
\text { C. }\end{array}$ & $\begin{array}{l}\text { The novice university } \\
\text { professor: tensions, } \\
\text { dilemmas and learning } \\
\text { at the beginning of the } \\
\text { teaching career }\end{array}$ & $\begin{array}{l}\text { Ciência e } \\
\text { Educação }\end{array}$ & $\begin{array}{l}\text { Didactics } \\
\text { and Higher } \\
\text { Education }\end{array}$ \\
\hline 2016 & David, RS. & $\begin{array}{l}\text { Contemporary teaching: } \\
\text { challenges for teachers } \\
\text { in higher education }\end{array}$ & $\begin{array}{l}\text { Caderno de } \\
\text { Letras }\end{array}$ & $\begin{array}{l}\text { Pedagogy } \\
\text { and Higher } \\
\text { Education }\end{array}$ \\
\hline 2017 & Cruz, GB. & $\begin{array}{l}\text { Didactics and teaching } \\
\text { in higher education }\end{array}$ & $\begin{array}{l}\text { Revista } \\
\text { Brasileira de } \\
\text { Estudos } \\
\text { Pedagógicos }\end{array}$ & $\begin{array}{l}\text { Didactics } \\
\text { and Higher } \\
\text { Education }\end{array}$ \\
\hline
\end{tabular}

Fonte: Autor.

De acordo com a tabela de estudos encontrados na literatura seguem abaixo um resumo das pesquisas recentes de diversos autores sobre a didática em docência do ensino superior, suas contribuições e desafios.

Esteves (2008) contextualiza a pedagogia do ensino superior em domínio gerais dos objetivos a se alcançar, das políticas educativas e exigências sociais. Faz reflexões a respeito do ensino centrado no aluno, em que a autora acredita ser a primeira condição, mas não única, para se alcançar a excelência pedagógica no ensino superior. Para isso, é preciso investimento na formação pedagógica dos docentes universitários.

Cavaliere Junior et al. (2009) realizam um estudo sobre a afetividade e aprendizagem na docência do ensino superior para alertar docentes para prestar atenção em suas 
responsabilidades com os discentes e a sociedade. Discorrem sobre a necessidade de estes profissionais trazerem harmonia para a sala de aula, serem criadores e motivadores dos alunos, além de comprometimento e ética com eles. Apontam que transferir conhecimento é diferente de aprender, pois aprendizado é quando entra e permanece no cotidiano dos discentes, é apreender o conhecimento. Também é importante a questão da escuta aos seus alunos o que traz em seu bojo humildade e afetividade para orientar os educandos.

Albuquerque (2010) realiza uma pesquisa para compreender a percepção de professores e alunos no processo de ensino-aprendizagem acerca do significado de "bom professor", na prática características do professor eficaz. Então entrevistou 40 professores e 40 anos com perguntas e análise do conteúdo. As respostas foram categorizadas nos seguintes espectros: a) conhecimento específico, b) comunicação e linguagem, c) relacionamento, d) exigência, e) motivação, f) valores pessoais, g) cordialidade, h) recursos didáticos, e i) avaliação da aprendizagem. Sintetizando resultados referente a opinião de professores pode-se identificar que: a) para os professores do ensino superior o atributo mais relevante é "valores pessoais", já para os do ensino secundário é "conhecimento específico"; b) a comunicação e linguagem" é relevante para $60 \%$ de ambos grupos de docentes; c) a "motivação" e a "cordialidade" são apontadas por $40 \%$ dos docentes de ensino secundário, contra nenhuma menção dos docentes do ensino superior. Uma análise geral sobre os indicadores relevantes na resposta dos alunos associada ao professor eficaz são três pilares: "conviver", "conhecer" e "saber comunicar", como importantes para a qualidade do ensino-aprendizado.

Rodrigues, Moura e Testa (2011) abordam o tema da didática no ensino superior por meio de duas visões históricas: a tradicional e a moderna. Buscam identificar as diferenças entre estas perspectivas e compara os componentes didáticos básicos: professor, aluno, método, conteúdo e objetivo. Nas práticas pedagógicas do ensino superior, se infere que predomina a didática tradicional, centrada na preocupação com o "ensinar", apesar do perceptível avanço da didática moderna, centrada na preocupação com a "aprendizagem". Isto se deve a influência de preconceitos 
pedagógicos tradicionais, formação precária dos futuros docentes e a exigência do sistema educacional atual. Apesar disto, há muitos docentes do ensino superior que vem inovando suas práticas, tonando suas aulas um diferencial ao ensinoaprendizado.

Santo e Luz (2013) descrevem no artigo sobre a expansão do ensino superior e a qualificação dos docentes para responderem ao duplo desafio das exigências curriculares conteudistas e a conduta pedagógica na sala de aula. Discutem aspectos da didática no processo ensino e aprendizagem no ensino superior, visto que abordagens didáticas tradicionais deixam de atender as demandas contemporâneas. Concluem a pesquisa elencando da importância de uma reflexão da práxis didáticopedagógica do professor universitário perante as necessidades da sociedade atual e propõem sugestões didáticas para o processo ensino-aprendizagem em adultos de modo impulsionado.

Valente (2014) discute sobre as tecnologias digitais de informação e comunicação (TDIC) como importante mudança na educação à distância (EAD). Com elas foram criadas diversas modalidades de EAD, inclusive a blended learning [ensino hibrido], que combina atividades presenciais e à distância. Dentre estas combinações há a flipped classroom [sala de aula invertida] uma delas. De acordo com esta abordagem os conteúdos curriculares e orientações são repassados pelo docente em sala de aula, porém o discente estuda o material antes da aula, ocupando um espaço de aprender de maneira ativa, debatendo com professor e colegas. Esta metodologia de ensino é apontada por pontos positivos e negativos por inúmeros autores.

Oliskovicz e Piva (2014) por meio de revisão bibliográfica buscam estudos sobre o uso de estratégias didáticas como recursos para serem utilizadas pelos docentes em exercício e iniciantes para eficácia do ensino-aprendizagem. Tal pesquisa aponta que estas escolhas das técnicas de ensino ficam mais fáceis com tempo de experiência prática em sala de aula. E são através erros e acertos que se aprimoram as suas técnicas. 
Freire e Fernandez (2015) realizam uma pesquisa com docentes de uma universidade pública para compreender como eles percebem os agentes da área educacional, e como são gerenciadas as tensões e dificuldades no inicio da profissão. Utilizam o referencial teórico de Pierre Bourdieu, sobre o espaço e poder simbólico, no qual as lutas dos agentes determinam, validam, legitimam representações. As entrevistas são semiestruturadas, avaliadas por análise do conteúdo. Os resultados apontam para dificuldades no manejo da sala de aula e similaridade entre docentes com e sem experiência: insegurança didática, valor dado ao apoio (ou não) dos colegas de trabalho, e quantidade de atividades realizadas. Mostra-se, ainda, uma relação de dominação dos docentes mais experientes sobre os novatos, refletindo a diferenciação de capital cultural e simbólico de quem adentra uma nova área.

David (2016) em sua pesquisa fala sobre os desafios do trabalho do profissional docente no ensino superior e práticas necessárias para o ensino e aprendizagem para construção do conhecimento no ambiente institucional. Retrata desafios perante os alunos de hoje em decorrência da mudança de comportamentos, prioridades e valor para educação acadêmica. Conclui relatando o quanto se exige desempenho, humanidade, rendimento e habilidades do profissional para diversas tarefas, o que gera desgaste físico e emocional. Porém, o docente tem uma baixa remuneração o fazendo buscar mais trabalho, gerando estresse.

Cruz (2017) em seu trabalho discute a relação didática e docência no ensino superior, por meio de três perspectivas de análise. Na conceitual, teorias epistemológicas que estruturam a didática e o espaço que ocupa na base de conhecimento do docente; na contextual, descreve o contexto de produção sobre a docência do ensino superior; e, na investigativa, mostra resultados de pesquisas da formação em didática de futuros docentes, na visão de professores universitários e alunos de licenciatura. Por meio de autores referência sustenta-se a ideia que o domínio da didática é potencial para ensinar em qualquer nível acadêmico, inclusive na educação superior.

Com base nos referenciais teóricos para a prática didático-pedagógicas em docência do ensino superior é que citaremos contribuições de diversos autores a seguir. 
Um dos desafios da didática é articular os conhecimentos adquiridos sobre "o como", "para quem", "o que" e "por que" ensinar. A didática é um dos objetos de estudo da pedagogia sobre o desempenho do ensino por meio de elementos (conteúdos, aprendizagem e ensino) pautados numa concepção teórica educacional para elaborar critérios que direcionam a prática técnica dos professores (LIBÂNEO, 1990).

A didática é a "teoria da instrução e do ensino" que deve ser entendida como totalidade abrangente, que "investiga as condições e formas que vigoram no ensino e, ao mesmo tempo, os fatores reais - sociais, políticos, culturais, psicossociais - condicionantes das relações entre docência e aprendizagem". Para ele, o objeto de estudo da Didática é o processo de ensino, sua finalidade é "proporcionar aos alunos os meios para que assimilem ativamente os conhecimentos" (LIBÂNEO, 1990, p. 52-54).

Ao longo do tempo, diversas propostas pedagógicas alternativas têm surgido para auxiliar no complexo de processo ensino-aprendizagem. Diversos estudos e experiências sobre a atuação de alunos e professores no âmbito escolar nem sempre apresentavam um satisfatório desempenho. Levantando-se a hipótese de metodologias fundamentadas em uma prática de ensino homogeneizadora, centrada na reprodução de modelos pré-estabelecidos pelo professor (ALMEIDA, 1985).

No livro sobre as "10 novas competências para ensinar", no item número três, o autor descreve sobre conceber e fazer evoluir os dispositivos de diferenciação, fala da administração da heterogeneidade no âmbito de uma turma, pois embora os alunos tenham aproximadamente a mesma idade, há uma disparidade nos seus diferentes níveis de desenvolvimento (PERRENOUD, 2000a).

A educação tradicional tem dado ênfase à imagem do professor como detentor do saber e responsável pela transmissão do conhecimento, por outro lado, algumas vertentes teóricas vêm destacar não somente a importância do professor, mas também o papel do aluno como ser aprendente e ativo na construção de seu conhecimento. 
Freire (1996) relata que há metodologias de ensino que estão centradas na pedagogia tradicional, bancária, em que o professor "deposita informações no aluno", tornando o educando um mero expectador no processo de ensino-aprendizado. Em contraponto, apresenta uma proposta de pedagogia progressista, libertadora, que considera o sujeito como pensante e ativo.

Transferir conhecimento é diferente de ensinar, é criar oportunidades para a sua própria construção e produção. Quando o docente entra numa sala de aula deve ser receptivo a questionamentos e curiosidade dos alunos, a suas inibições: um ser inquiridor, inquieto e crítico diante da tarefa do professor que é ensinar (FREIRE, 1996).

No que tange a relação professor-aluno, Costa (2008) refere que há dois tipos de professores: o aulista e o pesquisador. Diante do processo ensino-aprendizagem, o primeiro ocupa-se simplesmente com a transmissão de conhecimentos; o segundo motiva, orienta, entusiasma, ampara e cobra o melhor desempenho do aluno de maneira que ele não aceite de modo passivo o conhecimento que the é passado, mas que pesquise e reconstrua seu conhecimento próprio.

Freire (1996, p. 22-23) descreve que não há professor sem aluno, ambos estão envolvidos num processo dialético do ensino-aprendizagem. Em suas palavras "Não há docência sem discência, as duas se explicam e seus sujeitos apesar de diferenças que os conotam, não se reduzem à condição de objeto um do outro. Quem ensina aprende ao ensinar e quem aprende ensina ao aprender".

Apesar da burocracia institucional, é a interação professor-aluno que vai direcionar o processo educativo de aprendizagem do aluno, portanto cabe a ambos os atores determinarem o clima desta relação (SANTOS, 2001, p. 72).

O processo educativo deve ser entendido em sentido amplo, nas palavras de Freire (1996, p.143) "a prática educativa é tudo isso: afetividade, alegria, capacidade científica, domínio técnico a serviço da mudança ou, lamentavelmente, da permanência do hoje [...] educação friamente tecnicista". Para ele a educação não 
deve ser fria, sem alma; com repressão dos sentimentos, emoções, desejos e sonhos, como uma ditadura racionalista.

Em sala de aula, a presença do afeto e da paixão do professor, influencia os alunos no aprendizado, mas também interfere consideravelmente no seu desenvolvimento e produção (ALVES, 2010). O educador tem uma função muito importante na vida acadêmica do educando, pois "educar antes de tudo é mobilizar o aluno para que se torne um aprendiz" (PERRENOUD, 2000b).

O papel do professor, antes concebido como único detentor do saber, mudou, pois se retrata como um facilitador do processo de ensino-aprendizagem, pois o principal ator é o discente. $O$ docente deve ensiná-lo a questionar, a pensar e a aprender a captar a sua realidade, para que possam formar opiniões pessoais (DAVID, 2016).

Tomando Margaret Mead (1961) como ponte para educação no ensino superior "debe enseñarse a las niñas como pensar, no qué pensar [...]. Debe enseñarseles que se los cuales es chos caminos, ninguno de los cuales es obliagtorio en sí, y que solamente a ellas cabe la responsabilidad de elegir". Palavras que traduzem o modo de produzir o cotidiano educacional de sucesso em que "as crianças devem ser ensinadas como pensar e não o que pensar [...]. Deve ensiná-las quais os caminhos, nenhum dos quais é obrigatório em si, e que somente cabe a elas a responsabilidade de escolher" (MEAD, 1961, p. 251, grifo meu). Educação esta, que não se aplica apenas ao contexto infantil, mas a qualquer fase do desenvolvimento humano.

A missão do educador não é dar respostas prontas, mas conduzir o educando a pensar e imaginar, para que se torne o principal sujeito de seu aprendizado. Nas palavras de Alves "para mim esse é o objetivo da educação, criar a alegria de pensar" (ALVES, 2000, p. 38). E ainda, "a missão do professor é provocar a inteligência, é provocar o espanto, é provocar a curiosidade" (ALVES, 2001, p. 22). 


\section{CONSIDERAÇÕES FINAIS}

Diante dos estudos e arcabouços teóricos de propostas didático-pedagógicas é possível compreender a diversidade de técnicas e estratégias a serem empregadas no ensino-aprendizagem da educação em nível superior. Outro ponto a se observar é que apesar da mudança no cenário social, que exige novas respostas para a educação, e avanços de uma proposta didática moderna, ainda há uma persistência em utiliza-se de abordagem didática tradicional, tendo o professor como o único detentor do saber e o aluno como único aprendente no processo educacional, como uma taboa rasa. Sem contar as barreiras institucionais que os professores enfrentam por apresentarem o "novo", o novo jeito de fazer.

Há que se destacar a necessidade de melhor formação para o professorado e melhor remuneração, pois interfere na autoestima profissional, podendo levar ao desgaste, físico e emocional, por abraçar várias fontes de trabalho. Quanto à relação professoraluno, apresenta-se a importância de um trato humano, de troca de saberes, afetiva e ética. Tendo o professor como fonte motivadora do aluno e do processo de aprender; e tendo o aluno como ativo em seu processo educacional.

Um das questões abordadas nestas pesquisas são as tecnologias da informação e comunicação (TIC), que tem se expandido fortemente no cotidiano das pessoas e ocupa grande parte do tempo. Elas podem ser muito úteis no desenvolvimento educacional, como a interação professor-aluno e aluno-aluno para discussão de conteúdos teóricos e troca de saberes.

Todos estes apontamentos poderão favorecer o insucesso ou sucesso do ensino e aprendizagem na interação professor e aluno, pois ambos são responsáveis neste processo. Para finalizar, o pensamento nasce de forças motrizes como a necessidade e o afeto positivo (afetividade) é a fome que põe em funcionamento o aparelho pensador. Fome é afeto. O pensamento nasce do afeto, nasce da fome (ALVES, 2000). 


\section{REFERÊNCIAS}

ALBUQUERQUE, Carlos. Processo ensino-aprendizagem: características do professor eficaz. Millenium, n. 39. p. 55-71. Out. 2010 Disponível: <http://repositorio.ipv.pt/bitstream/10400.19/470/1/Processo\%20ensinoaprendizagem.pdf>. Acesso em: 21 jan. 2019.

ALMEIDA, Stela Maris Velloso de. Metodologia alternativa para a prática de ensino. Educação, Curitiba, v. 4, n. 1, p. 93-107. Jan./Jun., 1985.

ALVES, Rubem. A alegria de ensinar. 8. ed. São Paulo: Papirus, 2000.

ALVES, Rubem. Ao professor, o meu carinho. São Paulo: Verus Editora, 2010.

ALVES, Rubem. Estórias de quem gosta de ensinar. 7. ed. São Paulo: Papirus, 2001.

CAVALIERE JUNIOR, Ezio; et al. A afetividade e a aprendizagem na docência do ensino superior. Revista Digital, Buenos Aires, ano 14, n. 131. Abr. 2009. Disponível em: $\quad$ <https://www.efdeportes.com/efd131/a-afetividade-e-aprendizagem-nadocencia-do-ensino-superior.htm>. Acesso em: 21 jan. 2019.

CRUZ, Giseli Barreto da. Didática e docência no ensino superior. Revista Brasileira de Estudos Pedagógicos, Brasília, v. 98, n. 250, p. 672-689, Dez. 2017. Disponível em:

<http://www.scielo.br/scielo.php?script=sci_arttext\&pid=S217666812017000300672\&lng=en\&nrm=iso $>$. Acesso em: 10 jan. 2019.

CUNHA, Ana Maria de Oliveira; BRITO, Taita Talamira Rodrigues; CICILLINI, Graça Aparecida. Dormi aluno(a) acordei professor(a): interfaces da formação para o exercício do ensino superior. Políticas de Educação Superior, [S. I.], n.11, p. 1-15. 2004. Disponível em: <http://29reuniao.anped.org.br/trabalhos/trabalho/GT11-2544-Int.pdf>. Acesso em: 10 jan. 2019.

DAVID, Ricardo Santos. Docência na contemporaneidade: desafios para docentes no ensino superior. Caderno de Letras, n.27, p. 233-240, Jul./Dez. 2016. Disponível em: 
<http://periodicos.ufpel.edu.br/ojs2/index.php/cadernodeletras/article/view/8960>. Acesso em: 21 jan. 2019.

ENRICONE, Délcia (Orgs.). A docência do ensino superior: sete olhares. Claus Dieter Stobäus [et al.] 2. ed. Porto Alegre: EDIPUCRS, 2008. 130p.

ESTEVES, Manuela. Para a excelência pedagógica do ensino superior. Sísifo. Revista de Ciências da Educação, n.7, p. 101-110. Set./Dez. 2008. Disponível em: $<$ https://www.researchgate.net/publication/28240672_Para_a_excelencia_pedagogic a_do_ensino_superior>. Acesso em: 21 jan. 2019.

FREIRE, Leila Inês Follmann; FERNANDEZ, Carmen. O professor universitário novato: tensões, dilemas e aprendizados no início da carreira docente. Ciência e Educação (Bauru), Bauru, v. 21, n. 1, p. 255-272, Mar. 2015. Disponível em: <http://www.scielo.br/scielo.php?script=sci_arttext\&pid=S1516$73132015000100016 \&$ Ing=en\&nrm=iso $>$. Acesso em: 21 jan. 2019.

FREIRE, Paulo. Pedagogia da autonomia: saberes necessários à prática educativa. São Paulo: Paz e Terra, 1996.

LIBÂNEO, José Carlos. Didática. São Paulo: Cortez, 1990. 263p.

MEAD, Margaret. Adolecencia y cultura en Samoa. 2. ed. Buenos Aires: Paidós, 1961.

OLISKOVICZ, Katiucia; PIVA, Carla Dal. As estratégias didáticas no ensino superior: quando é o momento certo para se usar as estratégias didáticas no ensino superior? Revista de Educação, v. 15, n. 19, p. 111-127. 2012. Disponível em: $<$ http://pgsskroton.com.br/seer/index.php/educ/article/view/1710/0>. Acesso em: 21 jan. 2019.

PERRENOUD. Philippe. Dez novas competências para ensinar. Trad. Patrícia Chittoni Ramos. Porto Alegre: Artes Médicas Sul, 2000a.

PERRENOUD. Philippe. Pedagogia diferenciada: das intenções a ação. Porto Alegre: Artmed, 2000b. 
POLITY, Elizabeth. Dificuldade de ensinagem. Que história é essa...? São Paulo: Vetor, 2002.

RODRIGUES, Leude Pereira; MOURA, Lucilene Silva; TESTA, Edimárcio. O tradicional e o moderno quanto à didática do ensino superior. Revista Científica do ITPAC, Araguaína, v. 4, n. 3, Pub. 5, Jul. 2011. Disponível em: <https://assets.itpac.br/arquivos/Revista/43/5.pdf>. Acesso em: 21 jan. 2019.

SANTO, Eniel do Espírito; LUZ, Luiz Carlos Sacramento da. Didática no ensino superior: perspectivas e desafios. Saberes, Natal-RN, v. 1, n. 8, p. 58-73, Ago. 2013. Disponível em: <https://periodicos.ufrn.br/saberes/article/view/2201/3366>. Acesso em: 21 jan. 2019.

SANTOS, Sandra Carvalho dos. O processo de ensino-aprendizagem e a relação professor-aluno: aplicação dos "sete princípios para a boa prática na educação de ensino superior". Caderno de Pesquisa em Administração, São Paulo, v. 8, n. 1, Jan./Mar. 2001. Disponível em: <https://www.sinprodf.org.br/wpcontent/uploads/2012/01/tx_5_proc_ens_aprend.pdf>. Acesso em: 10 jan. 2019.

VALENTE, José Armando. Blended learning e as mudanças no ensino superior: a proposta da sala de aula invertida. Educar em Revista, Curitiba, n. spe 4, p. 7997. 2014.

Disponível

em: <http://www.scielo.br/scielo.php?script=sci_arttext\&pid=S0104$40602014000800079 \&$ Ing=en\&nrm=iso $>$. Acesso em: 21 jan. 2019.

Enviado: Março, 2020.

Aprovado: Abril, 2020. 